ARTICLE

https://doi.org/10.1057/s41599-019-0231-z

\title{
Effective antimicrobial resistance communication: the role of information design
}

Sue Walker (i) ${ }^{1}$

\begin{abstract}
Getting the message across about the dangers of antimicrobial resistance $(A M R)$ and how to prevent it is a global priority. This article discusses the role of information design in the effective communication of information about $A M R$, and suggests that the design process-user input, iteration and consideration of circumstances of use-is key to successful communication. To illustrate this, using material from the Otto and Marie Neurath Isotype Collection at the University of Reading, this article considers the work of Otto and Marie Neurath who developed the Isotype system for visual education in the 1920s. They collaborated with scientists, writers and illustrators to ensure that messages were both accurate and relevant for their intended audiences, so that people could make their own decisions based on factual explanation. Their use of pictograms and schematic illustrations, consistent use of colours to represent meaning, and carefully considered relationships between text and image provided a distinctive visual 'look and feel'. The charts designed by the Neuraths to educate people about health included a series made in the 1930s for the US National Tuberculosis Association to explain the dangers of, and how to prevent TB. This article reviews how these charts were designed, including the designated role of the 'transformer' who worked to ensure that scientific facts were presented in an understandable form. The way of working and the verbal and graphic characteristics of the charts deserve serious consideration for effective communication of information about AMR today. Particularly relevant are the use of schematic images using scale and simplification to attract attention, the use of story-telling to engage people, not overwhelming readers with too much information, and using straightforward language. The article asserts that cross-disciplinary working is key to successful explanation about the dangers of AMR. It illustrates this with reference to a research project, influenced by the Isotype approach to public health communication, that brings together academics and practitioners in information design, architecture, ergonomics and human factors, and pharmacy in communicating information about AMR to people using community pharmacies.
\end{abstract}

\footnotetext{
${ }^{1}$ University of Reading, Reading, UK. Correspondence and requests for materials should be addressed to S.W. (email: s.f.walker@reading.ac.uk)
} 


\section{Introduction}

his paper draws attention to the role of design in the effective communication of information about antimicrobial resistance (AMR). It considers the work of Otto and Marie Neurath who developed the Isotype system for visual education in the 1920s, and in particular how their working method and systematic approach to designing has relevance to health communication today. It considers how information design in particular can help to address the AMR communication challenge.

Emmanuel Tsekleves and Rachel Cooper's recent edited volume, Design for Health (Routledge 2017), identified health communication as an 'opportunity' to apply design methods and approaches to offer value and benefit within health (Tsekleves and Cooper 2017, pp. 388-408). It emphasises that design (not mere visual styling) is an embedded part of problem solving. Techniques such as co-design (for example, in public health with service users) and the development of prototypes for evaluation and review are widely used in design research, and relevant in addressing one of the strategic aims of the UK 5-Year AMR strategy 2013-18: how to 'improve the knowledge and understanding of antimicrobial resistance'. Information design research and practice can contribute to this challenge by:

- considering the selection and presentation of the information provider's message in relation to the purposes, skills, experience, preferences and circumstances of the intended users;

- making prototypes-often through co-design with information providers and intended users;

- finding out whether documents-either in development, or when completed-work for their intended audience and circumstances of use through qualitative and quantitative methods;

- offering creative solutions to the visual organisation of information through the treatment of the text and the design.

Information designers make complex information clearconsidering the needs of users, and the circumstances of use. Information designers may use words and/or pictures to deliver that information on paper, via digital devices, or on public information displays such as billboards or hoardings. In communicating information about public health, information designers use their methods to influence behaviour change; to explain the science behind illness and disease; and to provide materials to assist with treatment and care. They may work on public health campaigns, or on individual documents; they may work in an institutional context, such as a hospital, or on a smaller scale, such as a local primary school (see Coulter et al., 1998). Some information designers work with words, writing and copy-editing text so it is appropriate for particular users; others with images and photographs (Abraham and Kools, 2012). Information design is cross-disciplinary, including typography and graphic design, applied linguistics, applied psychology, ergonomics, and systems engineering and has been found to be particularly valuable in health communication (see Frascara, 2006, 2015; Black et al., 2017).

The interdisciplinarity of information design was recognised in an academic context in 1979 when Rob Waller and Bryan Smith launched Information Design Journal (IDJ), which aimed for dialogue 'between the researcher and the designer, the technologist and the social scientist, the psychologist and the educationalist, the specialist and the layman.' IDJ continues to be the leading international journal in the field, publishing papers on history, theory and practice of this still emerging academic discipline. Paul Stiff s essay about information design history (2005) maps key documents, people and events that have shaped information design, reminding us of the cross-disciplinary nature of the field. Nevertheless, despite having a history and trackrecord, information design tends not to be widely recognised and understood as a category within design research, nor externally by decision-makers who might improve information presentation by drawing on research findings. This paper aims to raise the profile of the theory, practice and history of information design, and its usefulness as a design discipline that has direct influence on people's everyday lives.

Many people associate information design (especially its history) with the visual presentation of particular kinds of information. Arthur Lockwood's Diagrams (1969) introduced a compelling range of statistical and explanatory diagrams and maps, and Edward Tufte's more recent books (1997, 2001), for example, contained beautiful, intriguing and often complex examples of information visualisations across time and place. The use of historical precedent to inform and inspire current decision making is an integral part of information design research ensuring discussion of context and its application in social, cultural, economic and educational aspects of life (see, for example, the historical perspectives section in Black et al., 2017, pp. 3-174).

The historical precedent for effective health communication that is a main focus in this paper is work undertaken by Otto and Marie Neurath. The Neuraths evolved a system of visual education known as the Vienna Method of Pictorial Statistics which was developed into Isotype (International System of Typographic Picture Education). Their work was concerned with a much broader field than health, but work they did in the USA, Europe and the UK in the 1930s and 1940s in relation to public health communication about tuberculosis, diphtheria, infection, and well-being has relevance to AMR communication today, particularly their method of working. Had AMR been the global threat that it is today, the Neuraths would no doubt have been called upon to get involved. As drug-resistant TB is one indication of AMR, the TB campaign in the USA provides a starting point to consider the presentation and use of graphic explanation in engaging the public. The Neuraths moved from Vienna to Oxford in the 1940s and continued work in health communication and other aspects of social policy, drawing on their TB work in the USA (see, for example, Burke et al., 2017 and, particularly in relation to health, the charts in Taylor, 1944). The Isotype materials discussed in this paper are from the Otto and Marie Neurath Isotype Collection at the University of Reading, UK. This comprehensive source comprises working documents and correspondence as well as published charts, books and other material. The collection is well-represented in Christopher Burke, Eric Kindel and Sue Walker's edited volume, Isotype: Design and Contexts 1925-1971 (2013).

\section{Otto Neurath, Isotype and graphic explanation for the people} Otto Neurath, the Austrian philosopher and sociologist, worked in 1920s Vienna to explain to people how social and economic issues affected their lives. Neurath aimed to provide ordinary people with information presented in an accessible way, so that they could make their own decisions based on factual explanations. Education, as opposed to persuasion, was fundamental to the approach taken by Neurath and his team. A venue for Neurath's work was the Gesellschafts- und Wirtschaftsmuseum in Vienna; the exhibition 'Wien und die Wiener' aimed to show in graphic form everyday life of the Viennese (Burke, 2013a, 2013b, pp. 21-102). The charts in the exhibition used, among other things, rows of pictograms to represent quantities, and to make 
relationships and comparisons (see illustrations in Burke et al., 2013, pp. 44-45). Neurath developed a set of rules and principles which set out the Isotype methods for visual education published as International Picture Language in 1936 (see Twyman, 1975; Reading, 1980). This included the Isotype principle: 'A sign is representative of a certain amount of things; a greater number of signs is representative of a greater amount of things' as well as rules for use of a carefully defined set of colours and associated functions (such as blue for water and air; green for outdoors). International Picture Language also reminds us that Isotype is more than rows of symbols used to represent numbers of people, showing examples of 'before and after' as a form of comparison, and narratives that can be made by combining pictograms. A fundamental part of the design process was to transform (that is, design) content so that it could be understood. Marie Neurath played a key role as a transformer on many projects from the 1920 s until the early 1970s. In an account of her work she explained this role and the ingenuity, care and attention to detail that it involved (Neurath and Kinross, 2009). The method of working has been highlighted by design scholars and researchers as having influenced information design research and practice. Robin Kinross (2017), discussing Isotype legacy, concludes that Isotype's relevance to current practice is indeed collaboration and discussion to enable 'ideas to grow', and that the process of transformation is integral to this. He notes:

The Isotype transformer worked on behalf of the public, representing its interests. This is the largest motive behind the search for clarity, honesty, and comprehensibility in the communication being made. As in its emphasis on the collaboration of different specialists in making work, here too Isotype prefigures information design (Kinross, 2017, p. 115).

Charts to explain the dangers of and prevention of TB. Otto Neurath's work with the National Tuberculosis Association (NTA) in the USA was instigated by Harry E. Kleinschmidt, its Director of Health Education. Kleinschmidt had visited Europe in 1935 and had travelled to the Hague to meet Neurath to understand more about Neurath's ideas for a 'visual method of teaching'. In 1936, Neurath travelled to the USA to work with the NTA (Ihara, 2013, pp. 318-319). Marie Neurath joined Otto and together they worked on a series of charts to explain the causes of and prevention of tuberculosis. The 20 charts 'Fighting tuberculosis' were printed in an edition of 5000 copies, which were distributed in the form of a travelling exhibition in the USA and Canada (Fig. 1). The charts demonstrated a number of Isotype principles that resulted in them being very clear examples of information design, notably simplified and consistent schematic representations combined with carefully edited text so that the meaning was clear.

In the context of public health communication, the process with which the TB charts were produced had demonstrable future benefit. The Neuraths understood the need to work with those who understood the science, as described here by Marie Neurath:

The Tuberculosis Association had as their office a single large room in the Rockefeller Center; desks everywhere, with enough distance between them; it was always easy to ask a specialist to come over. We quickly began to collaborate. We soon agreed about the use of colours for meaning: orange for healthy, black for ill and causing illness, red for medical measures, light blue for the air of the pneumothorax. We discussed the simplification of the representation of the lung, and the need to give it an enclosure-without this a pneumothorax would not be conceivable. Following previous accident protection

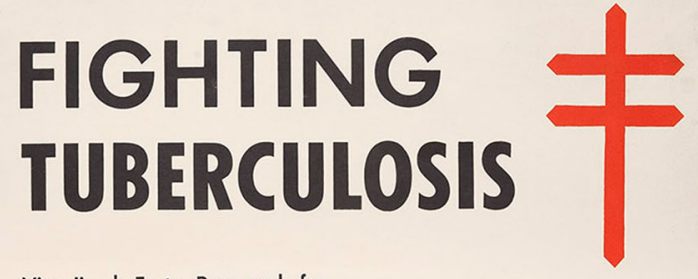

Visualized Facts Prepared for

\section{The National Tuberculosis Association}

by the International Foundation for Visual Education ISOTYPE

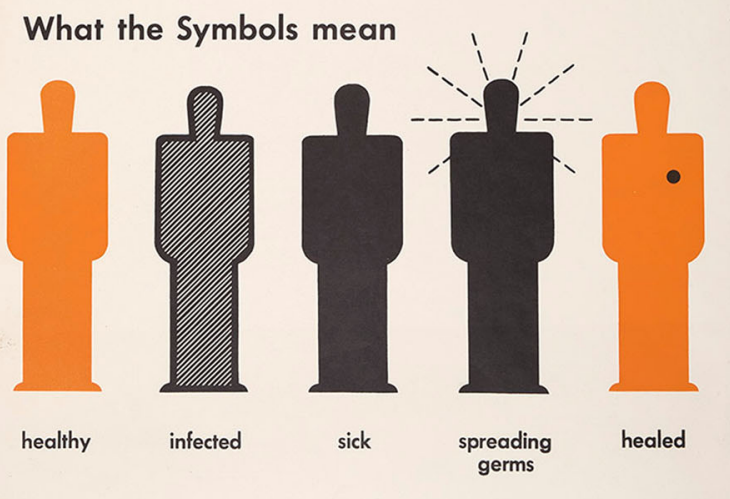

Fig. 1 Introduction from promotional material and the introductory chart for the 'Fighting tuberculosis' exhibition produced for The National Tuberculosis Association in the USA in 1938. This figure is not covered by the Creative Commons Attribution 4.0 International License. Reproduced with permission of University of Reading, Otto and Marie Neurath Isotype Collection, University of Reading

pictures, we were confident about charts such as those on possibilities of infection and on protection, but the more general requirement that an infectious invalid must be isolated demanded a more abstract presentation-one removed from the specific individual case. We surrounded the sick person with a continuous red line, indicating medical measures; this encapsuling [sic] blocked the dangerous black rays emitted from the invalid (Neurath and Kinross, 2009, p. 51).

This extract describes the process of making the charts, and the nature of the graphic decision making that lay behind them-the result of subject experts and the Isotype team working together iteratively.

As well as the graphic presentation of the information, Neurath considered how to engage people with it through exhibitions and displays in accessible venues, such as church halls, community centres and similar venues. In his work in Vienna, for example, Neurath displayed charts from the Gesellschafts- und Wirtschaftsmuseum in a small street-corner showroom of an insurance office, which attracted many visitors (Burke, 2013b, pp. 47-48). For the TB charts, the Neuraths produced a plan for their display in a travelling exhibition, providing instructions for the making of exhibition stands, as well as for the organisation of the 


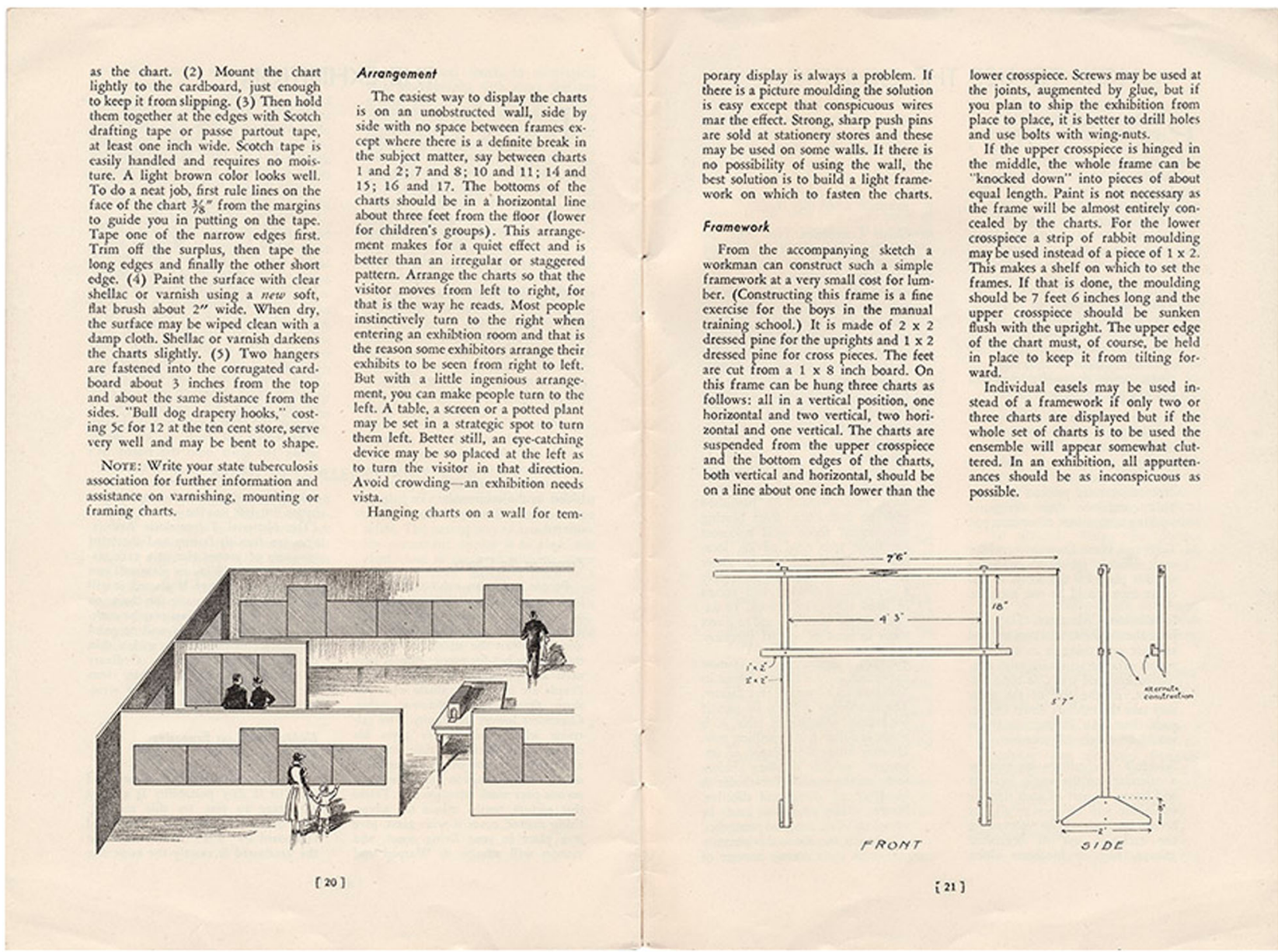

Fig. 2 Page from Teaching tuberculosis through the eye (National Tuberculosis Association, 1938, pp. 20-21) showing how to install the travelling TB exhibition produced for The National Tuberculosis Association in the USA in 1938. This figure is not covered by the Creative Commons Attribution 4.0 International License. Reproduced with permission of University of Reading, Otto and Marie Neurath Isotype Collection, University of Reading

charts as shown in Fig. 2 (see also Ihara, 2013, p. 333). The consideration of and use of space in this way draws attention to the 'circumstances of use' aspect of designing, of anticipating ways in which materials may be used.

In designing the charts, the Neuraths wanted to convey that people should take responsibility for their own health and that of their children, and the consequent beneficial impact that had on a particular community (Neurath, 1945, pp. 5-6). Writing in the UK Health Education Journal, and recalling the travelling TB exhibition, he noted:

Usually one started such exhibitions with pictures of healthy and sick lungs. We did so ourselves many years ago. But we found this was a scientist's start-why should the man in the street look at these lungs as something of importance?

We decided to start with a simplified story: a stranger enters a family, infects the husband with tuberculosis; the husband, his wife; the family is growing, some children get tuberculosis, one remains entirely healthy-that teaches the lesson: tuberculosis is infectious, but not hereditary (Neurath, 1944, p. 64)

This idea was expressed graphically in one of the TB charts, shown in Fig. 3. Figure 4 provides more detail on the transmission of germs via direct and indirect contact; while Fig. 5 is a cross-section view of how germs can travel from an infected lung to a healthy one. The Isotype TB charts exemplify many of the principles that Neurath and Kleinschmidt (1939) held to be essential for effective health education. The use of schematic images for scientific explanation meant that nonessential elements could be omitted. The modular and standardised pictograms that evoked simplicity and clarity were a key element of the Isotype approach, the result of much discussion and collaboration in the Isotype team (Burke, 2013a). Here, as in all the charts, colour is used consistently: orange to represent healthy; black to mean infected with TB germs (unhealthy); dark grey is used to denote infected but not yet spreading germs. A key, telling viewers about the meaning of the colours used in the chart, is given where relevant. Photographs were used occasionally as in Fig. 6 when it was important to convey individual differences. Here, photographs of people are used to attract attention, along with a question: 'Can you tell who has tuberculosis? Six have it.' This is followed by a chart giving the 'answers', that combined the photographs with schematic representations of TB symptoms.

The words used on the TB charts reflected Neurath's concern for clarity of expression and that words and images support each other:

Isotype is not intended to elbow words aside but to be used only in place of them when pictures promise to convey the idea better than words. Indeed, written words are used in 


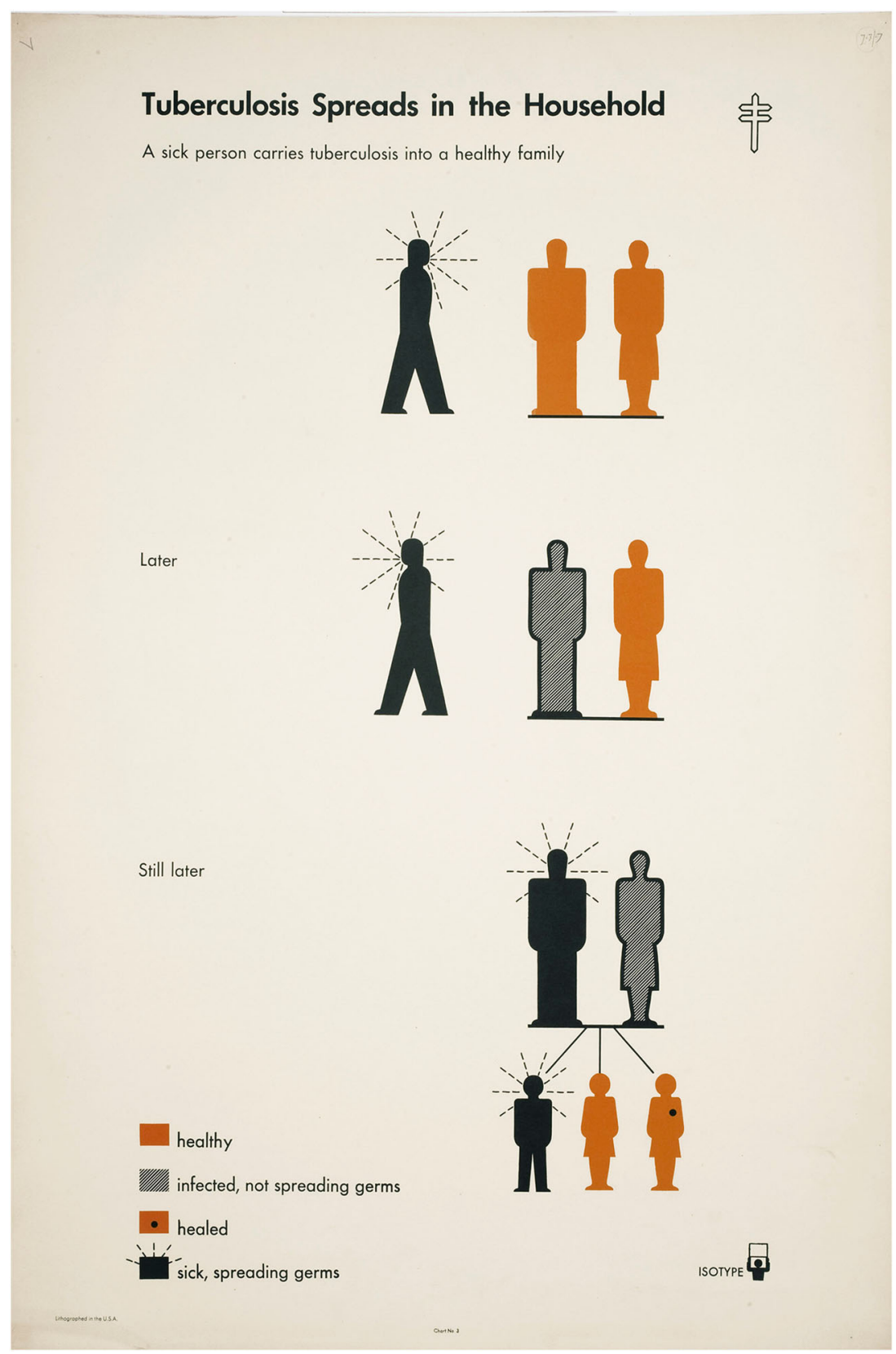

Fig. 3 'Tuberculosis spreads in the household', 1938. Chart from the 'Fighting Tuberculosis' exhibition produced for The National Tuberculosis Association in the USA. This figure is not covered by the Creative Commons Attribution 4.0 International License. Reproduced with permission of University of Reading, Otto and Marie Neurath Isotype Collection, University of Reading

conjunction with Isotype symbols, but as sparingly as possible (Neurath and Kleinschmidt, 1939, p. 5).

This can be seen in Fig. 7, the chart 'Only the doctor can tell who has tuberculosis'. Without the words it would not be immediately clear what is going on; but the words on their ownsuch as 'He has chest X-rays made'-are amplified by the image. The TB charts demonstrate comparison and contrast, a feature that Neurath and Kleinschmidt thought could enhance health communication. A good example is shown in Fig. 8. "The development of tuberculosis in the lung' repeats the person pictogram and the representation of the lung, so that the spread of TB can be seen and explained. Repetition of a more complex image is shown in Fig. 9, to make the point that social care is as important as medical care in recovery from TB.
To what extent was the NTA TB travelling exhibition a success? Marie Neurath reported on the extent and interest sparked by it affirming her belief in the accessibility of visual education:

The 5000 reproductions of our charts, in the size of the originals, went to all corners of the United States as a travelling exhibition, and it was reported that they were studied with great interest and understood by Inuit, Indians and everyone else alike. (Neurath and Kinross, 2009, p. 52)

However, her assertion that the charts were 'understood with great interest and understood by Inuit, Indians and everyone else alike' may have been aspirational. In the USA in the 1930s, even the idea of talking to users about educational materials was highly 


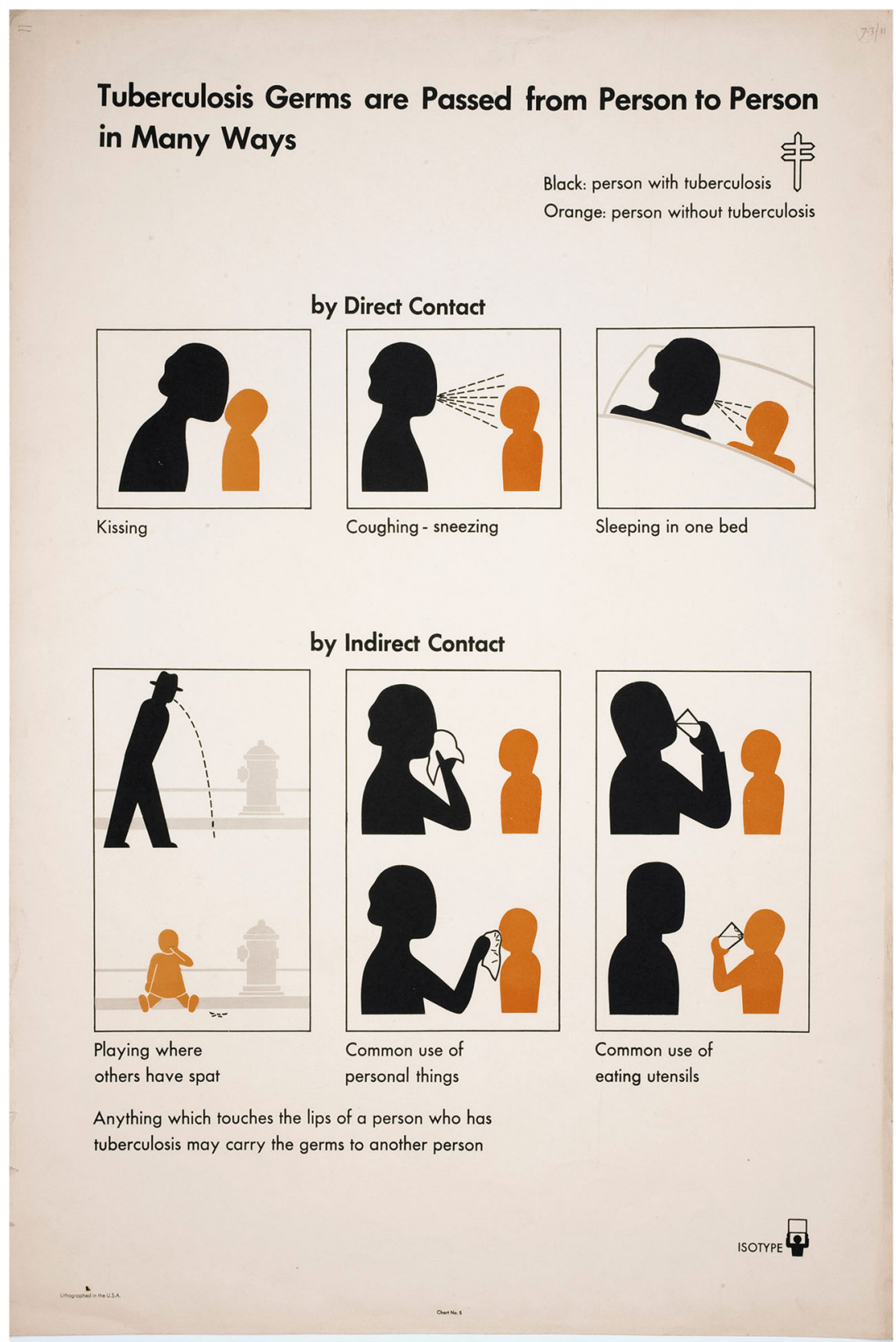

Fig. 4 'Tuberculosis germs are passed from person to person in many ways', 1938. Chart from the 'Fighting Tuberculosis' exhibition produced for The National Tuberculosis Association in the USA. This figure is not covered by the Creative Commons Attribution 4.0 International License. Reproduced with permission of University of Reading, Otto and Marie Neurath Isotype Collection, University of Reading

unusual, and there was no equivalent of today's awareness of inclusivity. But there may have been interest in the schematic presentation of information about TB which perhaps piqued curiosity and interest when compared with earlier health communication about $\mathrm{TB}$ which used a more representational style of illustration. Many of the materials produced by the NTA in the 1920s and 1930s, for example, used figurative interpretations of TB as a creature that had to be kept out of the house; or showed that a fit-looking person might have TB, or depicted fighting TB with science (see examples at NLM, 2011). Dori Griffin (2016) in her discussion of the USA Works Project Administration (WPA) public health posters produced in the 1930 s and 1940 s referred to the use of or reference to 'the simplified representational language of the Isotype pictorial system' showing examples of posters about breast and uterine cancer, and cancer treatments, noting that Isotype-style posters:

... received favourable reviews because of their graphic simplicity, their ability to intuitively communicate factual information and relationships, and their assumed (though of course not actual) universality. By adopting a similarly abstract and simplified visual style, the WPA's public health posters could trade on the associated visual messages of scientific accuracy and visual neutrality (Griffin, 2016, p. 133).

Isotype principles for health communication. Without the kind of user-testing that information design researchers would advocate 
today there is no evidence that tells us whether the charts were effective. Nevertheless, the NTA continued to produce the charts and in 1942 issued a booklet based on them, Modern Man Fights Tuberculosis (see Burke et al., 2013, pp. 349-353). Neurath and Kleinschmidt continued to promote Isotype as a tool for public health education through, for example, their 1939 publication Health Education by Isotype, a booklet illustrated with some of the

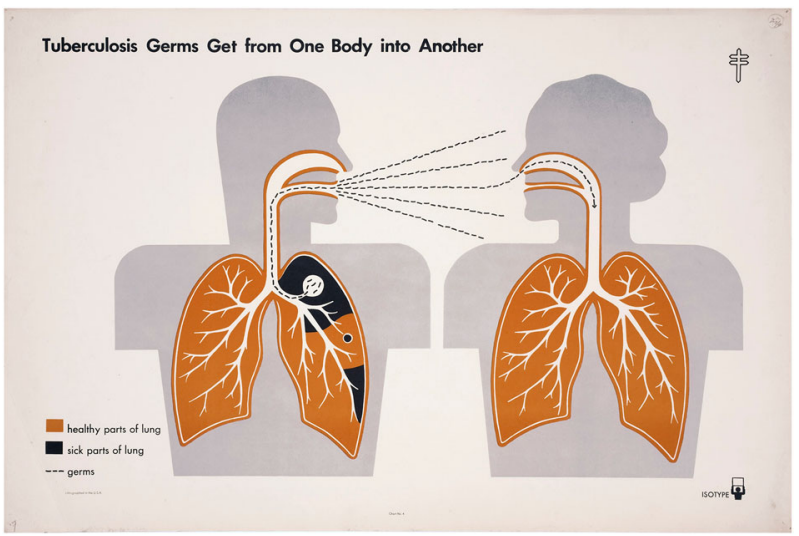

Fig. 5 'Tuberculosis germs get from one body into another', 1938. Chart from the 'Fighting Tuberculosis' exhibition produced for The National Tuberculosis Association in the USA. This figure is not covered by the Creative Commons Attribution 4.0 International License. Reproduced with permission of University of Reading, Otto and Marie Neurath Isotype Collection, University of Reading
TB charts. It identified the principles that they considered to be essential for effective health communication, and that remain relevant today. These can be summarised as:

- clear sequencing and ordering of ideas-in the case of the TB exhibition charts, for example, the idea was to start with the person and their family, then the scientific facts about the disease, and then the broader social and public health aspects of the disease:

- access for all-Isotype charts were designed to be understood by people of different levels of education, for example the description comparing the likely reactions of a 'person of very limited perception' and a 'professor of sociology' when they encounter the chart 'Tuberculosis spreads in the household' (Neurath and Kleinschmidt, 1939, p. 20);

- comparison and contrast-'to detect resemblances and differences is one of the important mechanisms of the learning process' (Neurath and Kleinschmidt, 1939, p. 22);

- schematic images are good for scientific explanation because they omit the non-essential elements and include only aspects that help the explanation;

- correlation-Neurath was keen to explain why things happened as they did and for example, made charts that linked health conditions with housing, education, working environments and so on;

- consistent use of colour on a chart or series of charts, such as red for protective measures, for example, representations of a doctor, or immunisation;

- transformation-where a 'transformer' (designer) works with a
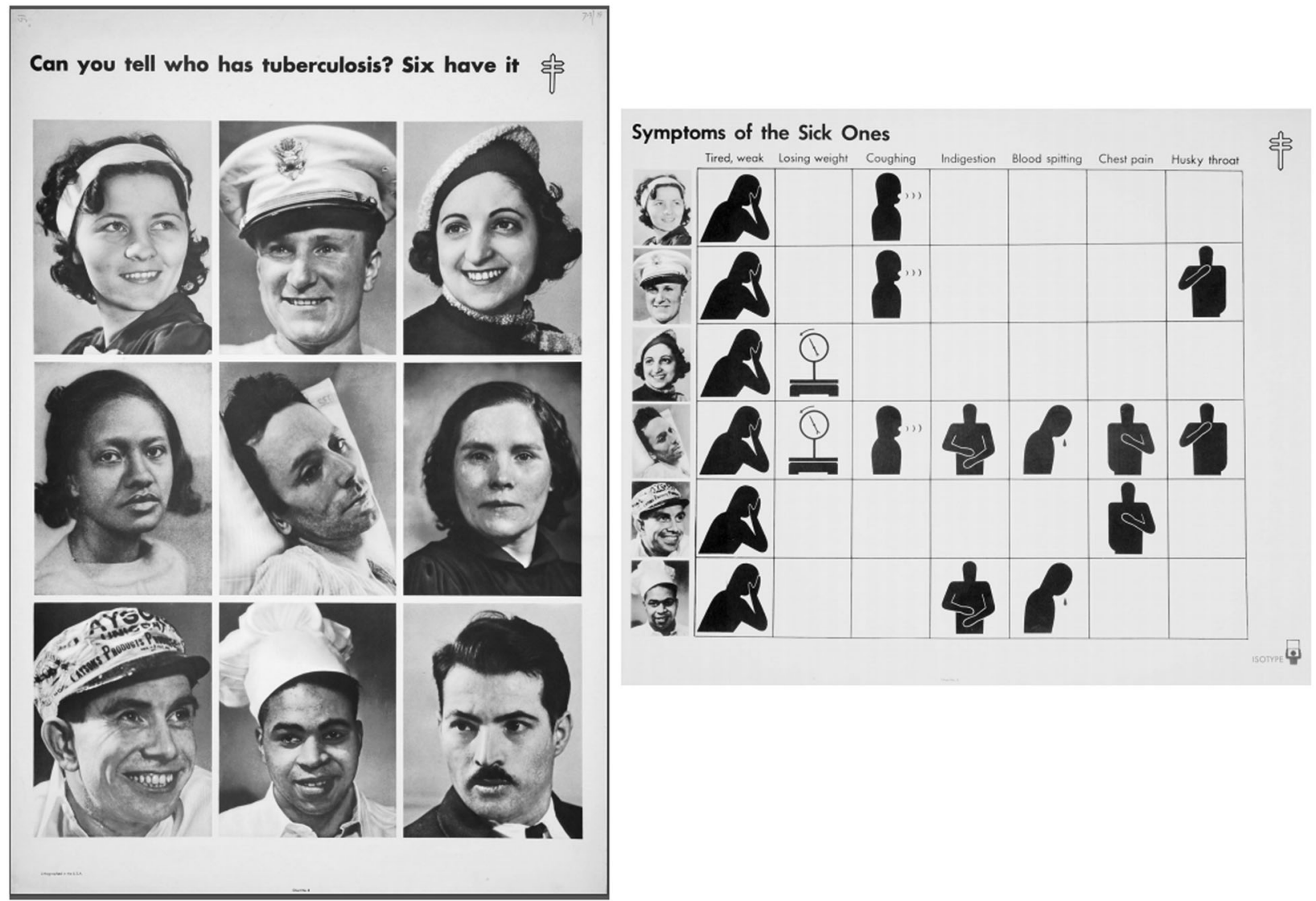

Fig. 6 'Can you tell who has tuberculosis?' and 'Symptoms of the sick ones', 1938. Charts from the 'Fighting Tuberculosis' exhibition produced for The National Tuberculosis Association in the USA in 1938. A pair of charts using photography as well as pictograms to engage the readers as they try to answer the direct question posed in the heading on the left-hand chart. This figure is not covered by the Creative Commons Attribution 4.0 International License. Reproduced with permission of University of Reading, Otto and Marie Neurath Isotype Collection, University of Reading 


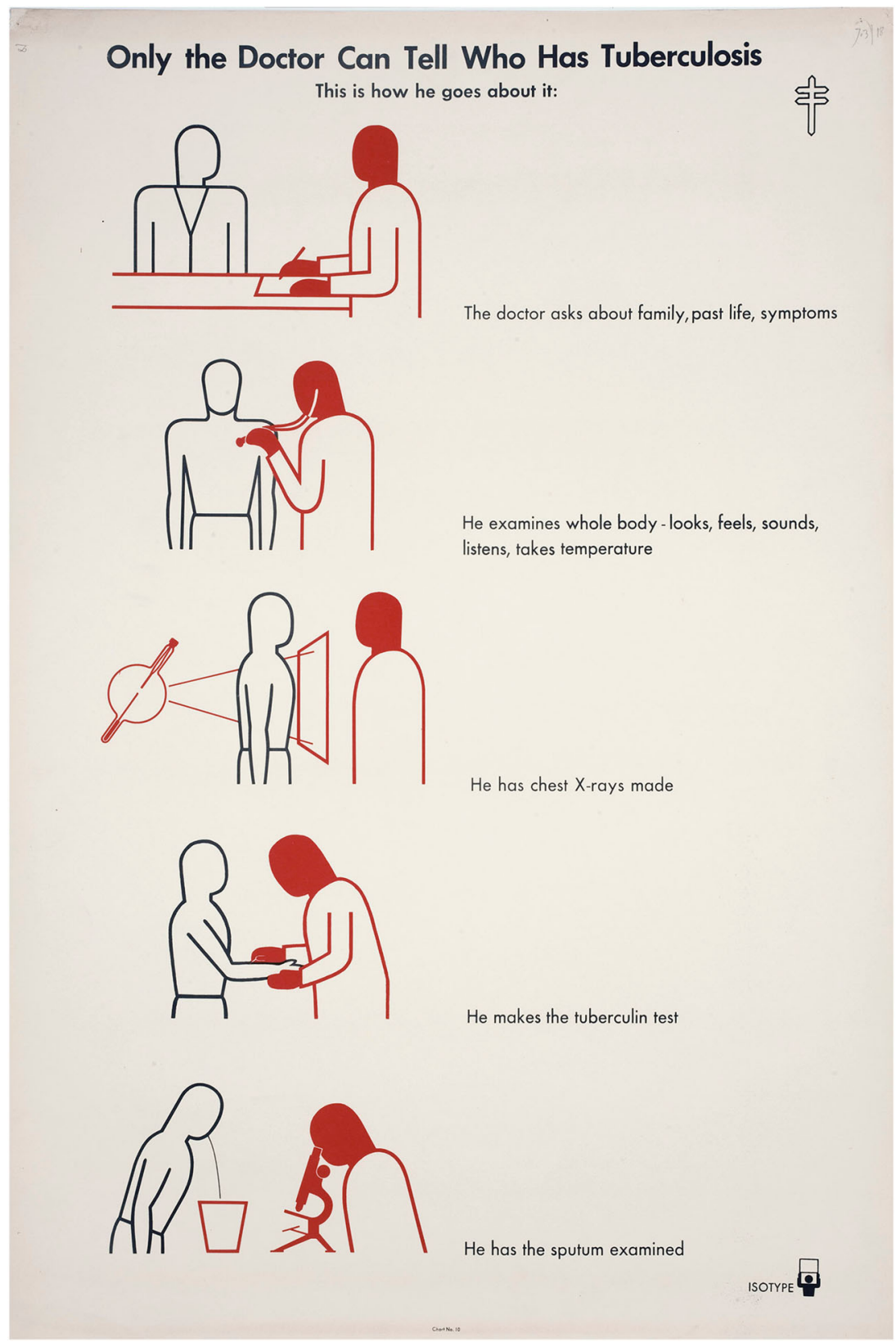

Fig. 7 'Only the doctor can tell who has tuberculosis', 1938. Chart from the 'Fighting Tuberculosis' exhibition produced for The National Tuberculosis Association in the USA. This figure is not covered by the Creative Commons Attribution 4.0 International License. Reproduced with permission of University of Reading, Otto and Marie Neurath Isotype Collection, University of Reading

specialist in a particular area to transform scientific facts into a form that would be understood by the general public.

These principles align with a systematic, procedural approach to designing, and it is this along with the way that the Neuraths collaborated with science and subject experts in articulating their messages that is an important aspect of Isotype legacy, and that has since been affirmed by information design research as noted, for example, in Schriver (1997), Raynor and Dickenson (2009), and Walker (2017).

However, for many the Isotype legacy is not the working method and approach, but the visual characteristics of the work. This was observed by Kleinschmidt after the publication of the 1939 Health Education by Isotype where he noted as a 'failure' the lack of uptake by public health workers of Isotype as a visual education method. He attributed this to the lack of understanding of the Isotype principles and methods, there being rather more to visual education than pictures of 'cute little men' (Kleinschmidt nd: $\mathrm{x}-9$, cited in Ihara, 2013, pp. 334-335). The 'cute little men' attribute of Isotype is what many would regard as its legacy today. The use of Isotype-like pictograms to stand for people continues to be used as a device in many forms of health communication, including in relation to what people can do to prevent drug-resistant infections. For example, in the poster shown in Fig. 10 issued by the Royal Pharmaceutical Society in 2017, schematic images have been 


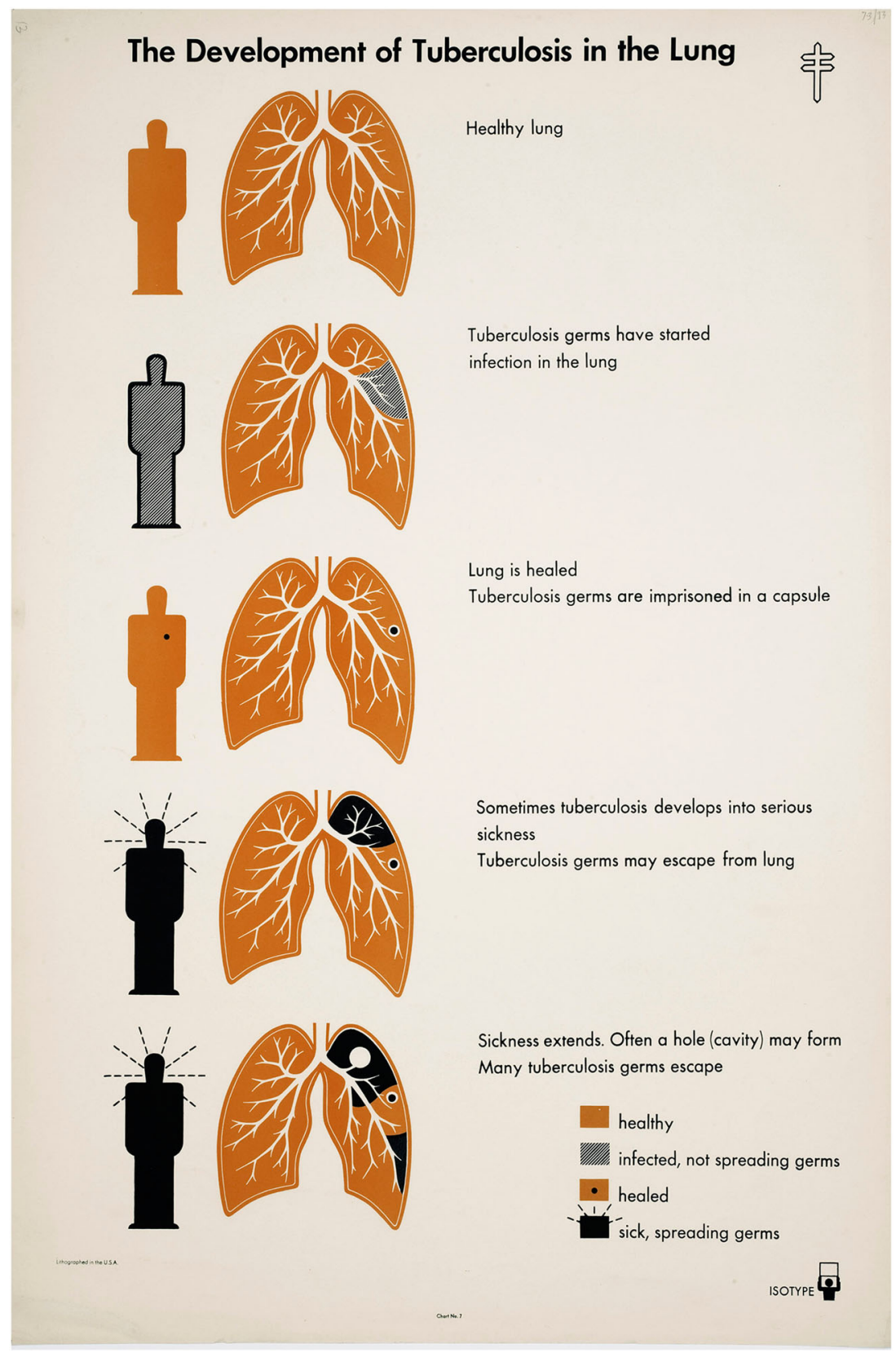

Fig. 8 'The development of tuberculosis in the lung', 1938. Chart from the 'Fighting Tuberculosis' exhibition produced for The National Tuberculosis Association in the USA. This figure is not covered by the Creative Commons Attribution 4.0 International License. Reproduced with permission of University of Reading, Otto and Marie Neurath Isotype Collection, University of Reading

used to encourage people to wash their hands. People pictograms are used to convey percentages, but the use of these 'little men' do not follow Isotype principles where percentages would be represented in relation to a consistent base (as demonstrated by the sketch below):

\section{0 \\ 000000000000000

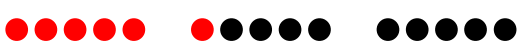

This use of space to denote units of information has been called 'marking off by Robin Kinross (2013 p. 132): 'the conventions of making pictograms into groups of five, ten, or some other number appropriate to the unit employed'. This aligns with principles of perception and supports 'at a glance' understanding of what is being expressed. This and other organisational principles of Isotype attract interest from cognitive psychologists, but usually without full understanding of what the Neuraths were trying to achieve. An example is given by Michael MacDonald Ross and Rob Waller (2000) where they discuss a misinformed translation of numbers into rows of pictograms in a study by psychologist Margaret Vernon in the 1940s making a comparison between the Isotype approach and line graphs. They argue that Vernon's chart is flawed, and include a (much better) version of the same information made by Marie Neurath, in retirement in the 1970s. A recent paper by Schreder et al. (2018) introduces intention to review Isotype principles from a 'cognitive-scientific' 


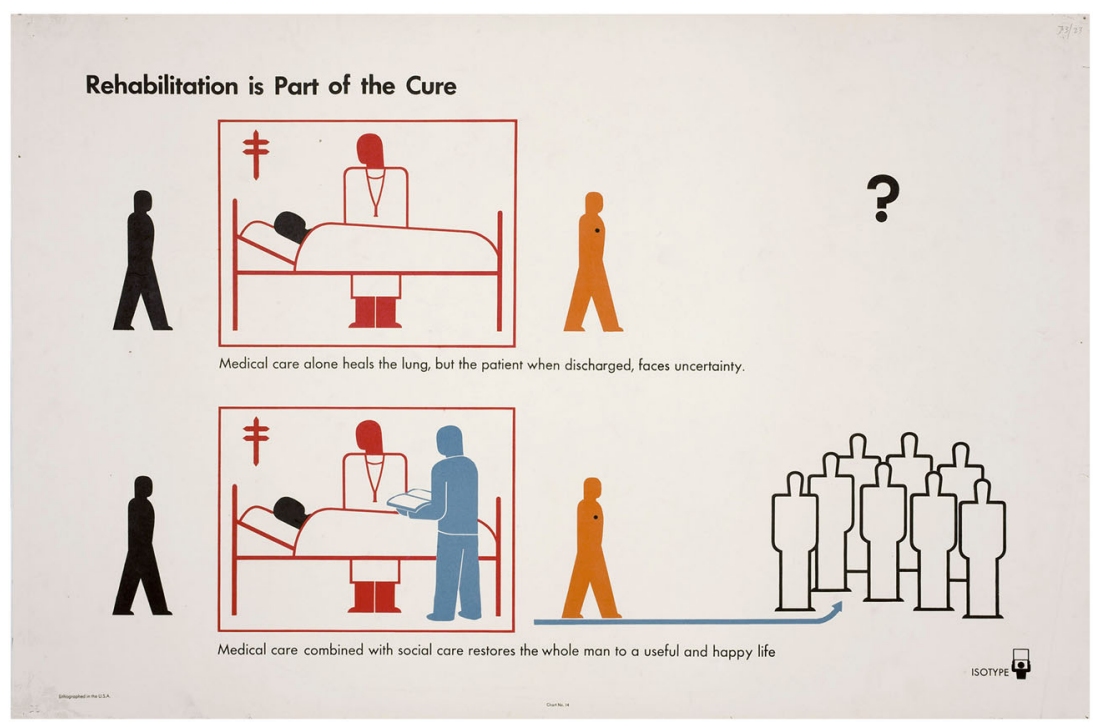

Fig. 9 'Rehabilitation is part of the cure', 1938. Chart from the 'Fighting Tuberculosis' exhibition produced for The National Tuberculosis Association in the USA. An example showing the powerful effect of comparison between a pair of images. This figure is not covered by the Creative Commons Attribution 4.0 International License. Reproduced with permission of University of Reading, Otto and Marie Neurath Isotype Collection, University of Reading

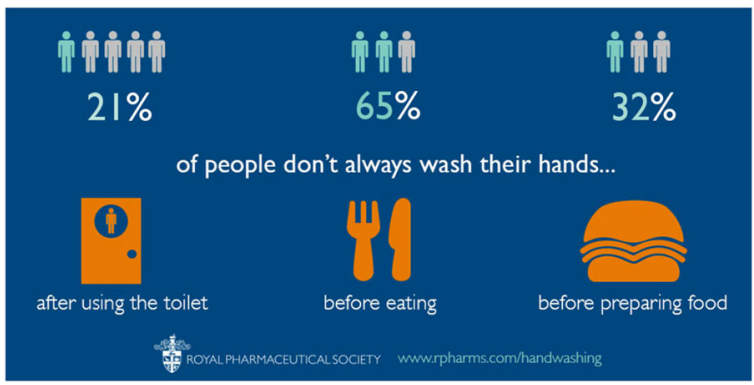

Fig. 10 One of a series of posters produced by the Royal Pharmaceutical Society (RPS) to raise awareness of the importance of handwashing, 2017. This figure is not covered by the Creative Commons Attribution 4.0 International License. Reproduced with permission of RPS; copyright (C) RPS, all rights reserved

perspective to gain understanding about the effectiveness of Isotype. Such approaches are to be welcomed, ideally taking account of Otto Neurath's life-long interest in maps, charts and other forms of schematic visual presentation as evidenced in his visual autobiography, From Hieroglyphics to Isotype (Eve and Burke, 2010). Such interests informed his personal understanding of the power of the visual in interpreting ideas, and underpinning principles of perception and visual logic. The use of schematic images prevails in much health communication, but few are used in the systematic and principled way that was the case with Isotype. In Fig. 11, for example, such images fulfil a decorative, associative function. Figure 12 shows use of pictograms of people to explain procedures, but in a less nuanced way than would have been the case if Isotype conventions had been applied, where at the very least there would have been differentiation between the sick person and the doctors and nurses.

Not all the Isotype explanations included pictograms of people. One of the Isotype TB charts, 'Fighting off attacks' aimed to explain resistance, though resistance in general relating it to a weak and a strong person, rather than resistance to antimicrobials (Fig. 13). Marie Neurath's explanation of how she and her team developed the graphic presentation for this concept is a

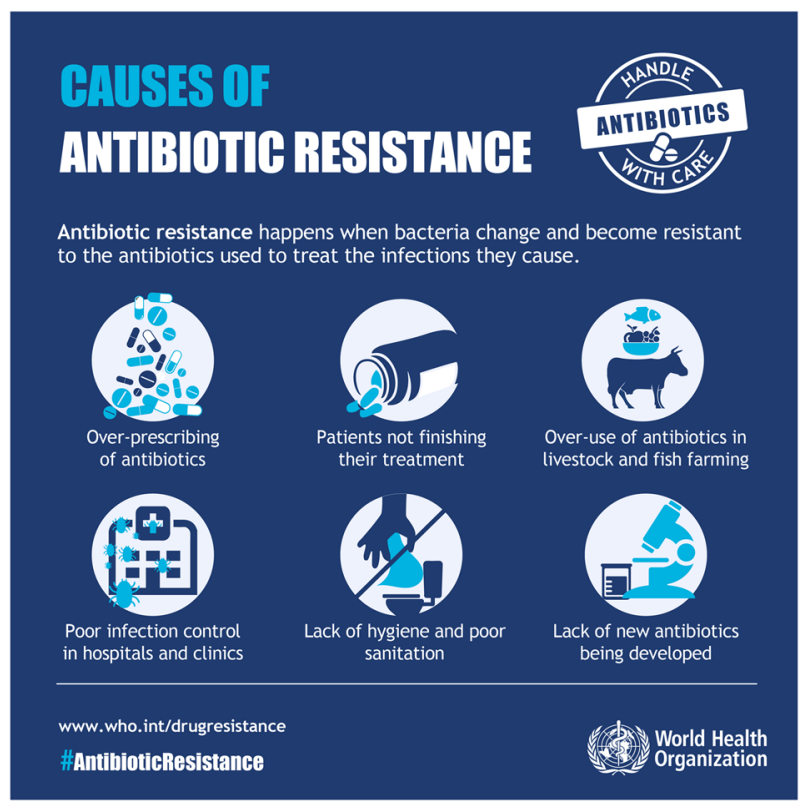

Fig. 11 One of a series of posters produced by the World Health Organisation as part of an antibiotic awareness week 16-22 November 2015. This figure is not covered by the Creative Commons Attribution 4.0 International License. Reproduced with permission of WHO; copyright (c) $\mathrm{WHO}$, all rights reserved

good example of the collaborative process through which the graphic explanation was developed, as well as demonstrating the thinking behind this particular design solution:

We introduced ... [an] abstract presentation for the concept of 'strength of resistance'. An allegorical presentation had been used earlier. This however was not really illuminating: it showed what happens if a strong man and a weak man have to carry an easy load, and if the strong man and the weak man have to carry a heavy load. Our presentation, more abstract and yet nearer to the situation, 

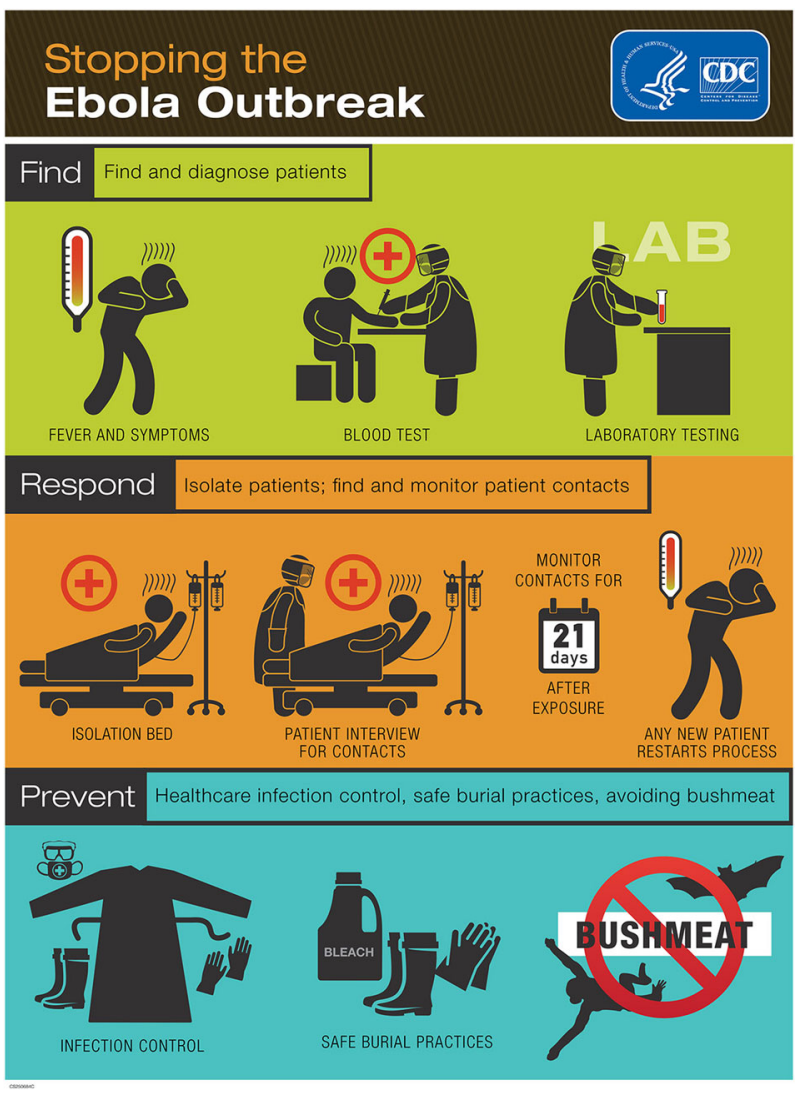

Fig. 12 Poster produced by the US Center for Disease Control and Prevention for the West African 2014-16 outbreak of Ebola. This figure is not covered by the Creative Commons Attribution 4.0 International License. Reproduced with permission of Centers for Disease Control and Prevention (CDC); copyright (c) $\mathrm{CDC}$, all rights reserved

showed a strong and a weak enclosure, and what happens if a weak attack of black arrows comes from outside (repulsion in the first case, partial penetration in the second) and what happens with a strong attack (partial penetration, complete splitting up). The enclosure here is nothing more than a curved line, orange in colour, thick or thin, indicating an inside and an outside. For me, this chart had something very convincing about it, and its validity is much more general than most of the other charts of the series (Neurath and Kinross, 2009, pp. 51-52).

This explanation of process provides evidence of the way that design can be used to develop ideas for the communication of abstract concepts. While this explanation conveys resistance of people rather than microbes, the graphic attributes may be transferable. Later work by the Neuraths extended their graphic 'abstract presentation' to a series of explanations about infection (Fig. 14). This work introduced 'defence bodies' and 'defence armies', represented by small red triangular shapes, and while the concept here related to maintaining a healthy body, it is entirely conceivable that the Neuraths would have extended this approach explain AMR.

Even though the TB charts were developed and produced in the 1930s, there is relevance to twenty-first century health communication, notably through iterative design, and a clear, systematic and accessible approach to graphic design. Consideration of the circumstances of use, even to the extent of supplying exhibition layouts for the TB charts, was unusual and distinctive at the time. Isotype continues to have contemporary acknowledgement in health communication. In their recent exhibition at
Wellcome, Can Graphic Design Save your Life?, curators Lucie Roberts and Rebecca Wright selected some of Marie Neurath's health communication work in the Western Region of Nigeria in the mid-1950s. They chose a poster-leaflet that explained diagnosis, treatment and cure of leprosy (Schrauwen et al. 2017: 167-73).

\section{Graphic explanation beyond Isotype}

Antibiotic misuse: campaigns, messages and positioning. The visual clarity and simplicity of Isotype graphic language has considerable appeal as affirmed informally in conversation with TB nurses working today, commenting on the chart illustrated in Fig. 5. However, this is just one approach to graphic explanation and more recent AMR communication includes cartoons, comics, powerful language and striking imagery to engage people. Notions of self-care such as handwashing and responsible use of antibiotics feature in many public health AMR interventions, and information is conveyed in different ways. The anthropomorphising of bugs and pills is a well-established approach shown, for example, in the first UK Department of Health antibiotic campaign in 1999. 'Andybiotic' was a cartoon character in the form of a pill used in a campaign in the late 1990s to increase people's understanding of when it was appropriate to use antibiotics (see illustration in Woodhead and Finch, 2007). The materials included visually striking posters where Andybiotic engaged in conversations with people to encourage them not to take antibiotics when they had a cold. The typography in these posters works on a number of levels from speech bubble comments from Andybiotic to strongly emphasised words 'don't work' that, along with rather uncomfortable cartoon-style illustrations, engage readers' attention. From 2008, involvement in European Antibiotic Awareness week by the NHS and Public Health England (PHE) saw the development of materials including posters and leaflets for use in hospitals and surgeries, as well as materials for billboards and hoardings. This campaign uses bright colours and simplified images to catch attention and typography is exploited to get across information about antibiotics. Text in all-capitals 'shouts' at the reader in many of the materials (Fig. 15). The 'Get well soon' information posters produced by Public Health England promoting their Antibiotic Guardian Campaign show a more information-rich example: visually, through the use of colour and pill image used here to fulfil the function of a bullet in a list, this document aligns with other materials in this campaign. ${ }^{1}$ However, the typography is not inviting for the reader-the lines of black type are too long; and there is little differentiation of content type (seen, for example, in the list of white type where two of the items are facts about antibiotics, and two are calls to action). Materials continue to be available for download via gov.uk including versions of some documents in languages other than English. An innovative intervention includes opportunity for engagement through asking people to pledge to become an 'antibiotic guardian'.

These campaigns attracted interest from researchers keen to ascertain whether or not such interventions increase awareness and change behaviours. In McNulty et al.'s (2007) survey of public awareness of antibiotics, participants were asked whether they were aware of the Andybiotic campaign and whether it had any impact on their behaviour. Their results suggested relatively low awareness (20\%), though it is difficult to disentangle any direct impact due to the broad range of questions in the survey. McNulty et al. (2010), in a review of the materials used in the 2008 campaign, some of which are shown in Fig. 15, suggested that they had little impact on people's awareness of antibiotic misuse. Chaintarli et al. (2016) assessed the impact of the Antibiotic Guardian campaign to tackle AMR on self-reported 


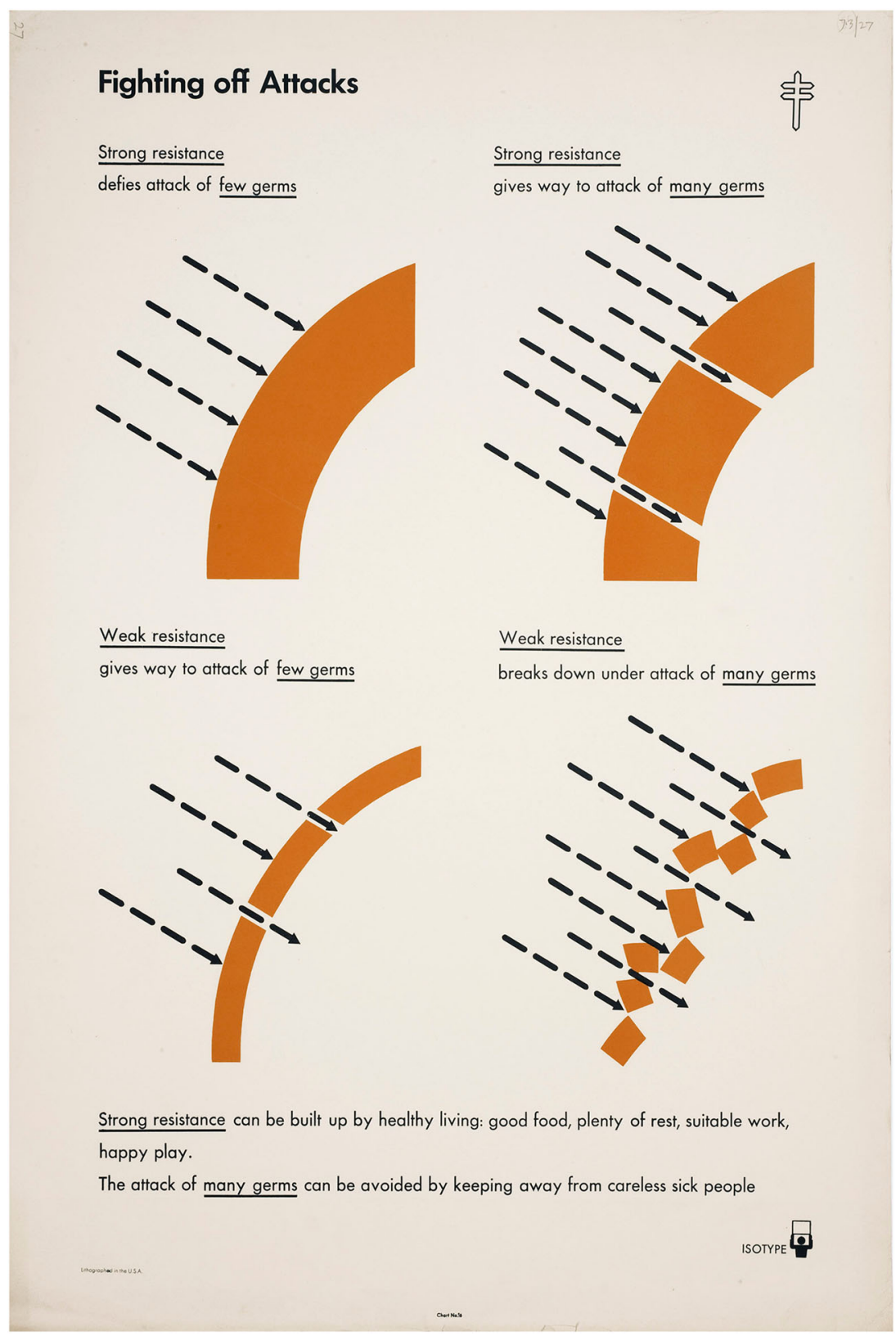

Fig. 13 'Fighting off attacks', 1938. Chart from the 'Fighting Tuberculosis' exhibition produced for The National Tuberculosis Association in the USA. This figure is not covered by the Creative Commons Attribution 4.0 International License. Reproduced with permission of University of Reading, Otto and Marie Neurath Isotype Collection, University of Reading

knowledge and behaviour change. They reported among other things an increased sense of personal responsibility for tackling AMR after the campaign, suggesting that the idea of a pledge reinforced personal commitment.

Other approaches rely less on images of germs and pills and focus on other visual forms of persuasion and influence. Strong messages predominate, and may be represented by words, images or through close interaction between the two. Figure 16 shows one of the posters in the 2014 WHO TB campaign and is an example of a puzzling message. This is one of a series-the others provide additional information. The 3 on the poster relates to the 3 million people who do not get the care they need when they have TB. Using scare tactics to engage people has been a wellused treatment both graphically and linguistically. Sara Kenney and John Watkiss's Surgeon X graphic novel (2017) combines fear-appeal tactics with a compelling and gripping story about a future in which antibiotics are no longer effective.

The Surgeon $X$ approach to AMR explanation demands close alignment of image and language with the comic book genre. Without the constraints of such conventions, finding words that work can be challenging not least because the use of the term 'anti-microbial resistance' is often misunderstood. A survey commissioned by Wellcome found that most people thought that anti-microbial resistance meant people's resistance to antibiotics, rather than the resistance of bacteria to treatment by antibiotics (Wellcome, 2015). This work fed into a joint comment published in Nature, with five authors, from South Africa, Switzerland, France and the UK, agreeing that failure to use simple, clear and consistent language risks undermining the global response to this urgent health threat (Mendelson et al., 


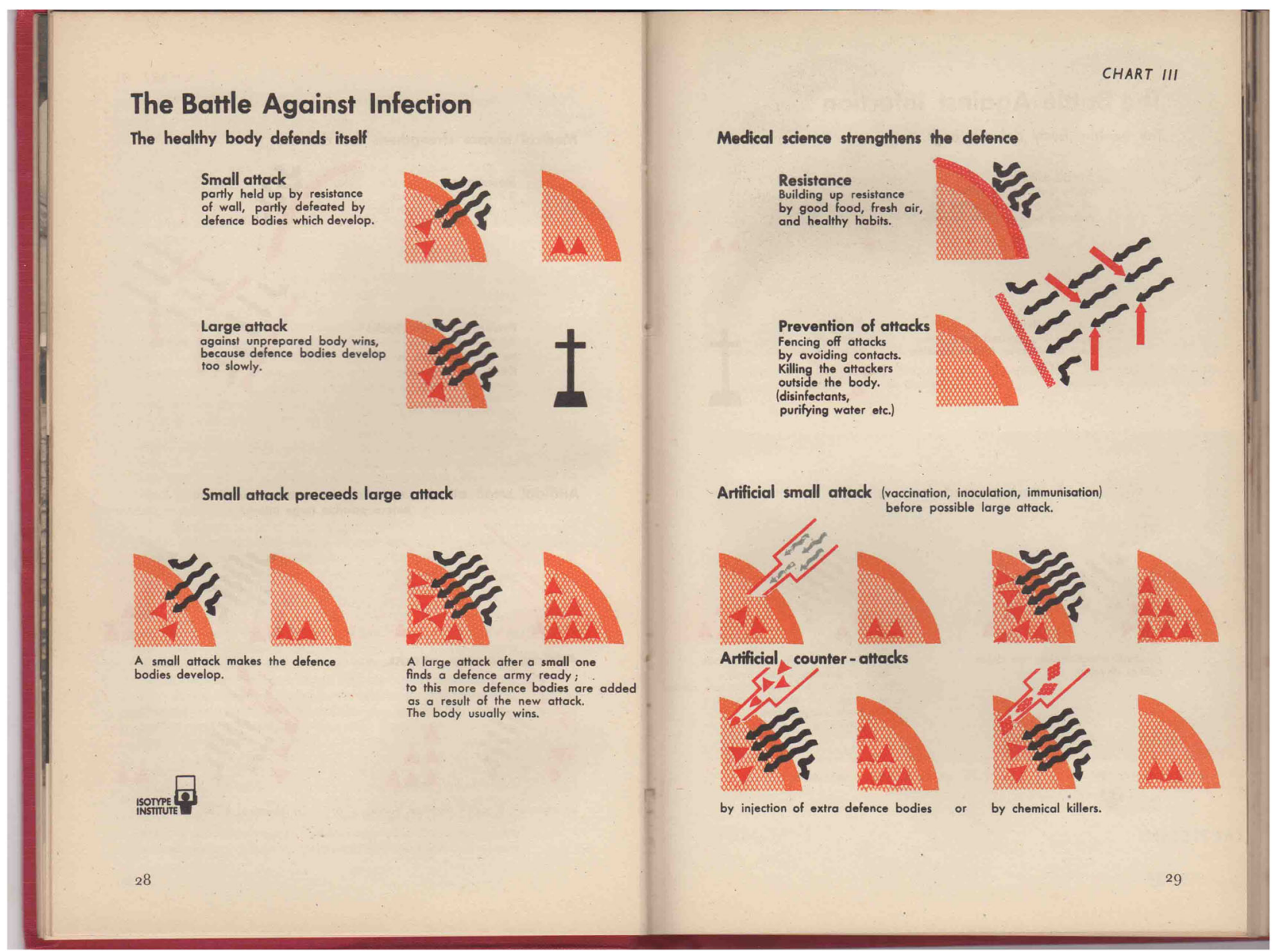

Fig. 14 'The battle against infection' from Stephen Taylor (1944). This figure is not covered by the Creative Commons Attribution 4.0 International License. Reproduced with permission of University of Reading, Otto and Marie Neurath Isotype Collection, University of Reading

2017). This group proposed that 'drug-resistant infections' should be used instead of 'anti-microbial resistance' as the overarching term in English for infections caused by bugs resistant to treatment, including antibiotics; and also that terms associated with war (combat, attack, etc.) could draw attention away from the positive role that bacteria play in human immunity, digestion and gut health.

For many people AMR awareness is related to a particular circumstance, such as a child with a fever, or a partner with a sore throat. In such situations, interventions may be small scale-a leaflet picked up or a poster seen in a doctors' waiting room; or a notice in a community pharmacy. Such small-scale interventions have a track record of success in health communication; as noted by Grace Rose (1994, pp. 104-105) in relation to blood and organ donation, suggesting that:

Written ephemera such as leaflets, pamphlets and booklets can play an important role in enabling informed decisions to be made. Such material is vital for conveying information briefly and simply, and ephemera often contains helpful information about high profile subjects.

She listed many outlets for and producers of such ephemera, drawing attention to the wealth of materials that people have access to. Rose also recognised the importance of design expertise and eliciting the views of intended users. She affirmed that information design has a role to play through the use of language, space and graphic conventions to clearly articulate the structure of health-related ephemera to convey meaning, in relation to intended particular circumstances of use (whether a series of poster or leaflets, a web site, and app or an exhibition). Smallscale, personally relevant interventions draw attention to the importance of place and the space in which people engage with AMR communication. Ward and Hawthorne (1994) found that patients in a GP's waiting room said they read and remembered the subjects of the posters displayed about healthy eating, stopping smoking, reducing alcohol consumption, and AIDS; McNulty et al. (2010), suggested that a waiting room environment and GP consultations might be an effective way to improve awareness of antibiotic use. Consideration of the place and circumstances of use is key to the way that information designers work.

A cross-disciplinary project: information design, architecture and pharmacy. In response to a UK research council call to consider how the indoor built environment could be used to activate interest in AMR, an AHRC-funded research project 'Information Design and Architecture in Persuasive Pharmacy Space: combating AMR' (IDAPPS) is considering how community pharmacies can be used to engage people with the AMR communication challenge. This project is taking inspiration from Isotype ways of working and approaches to graphic communication. Information design, architecture, human factors and ergonomics, behavioural science, and pharmacy academics and practitioners are working together, much as the Neuraths would 


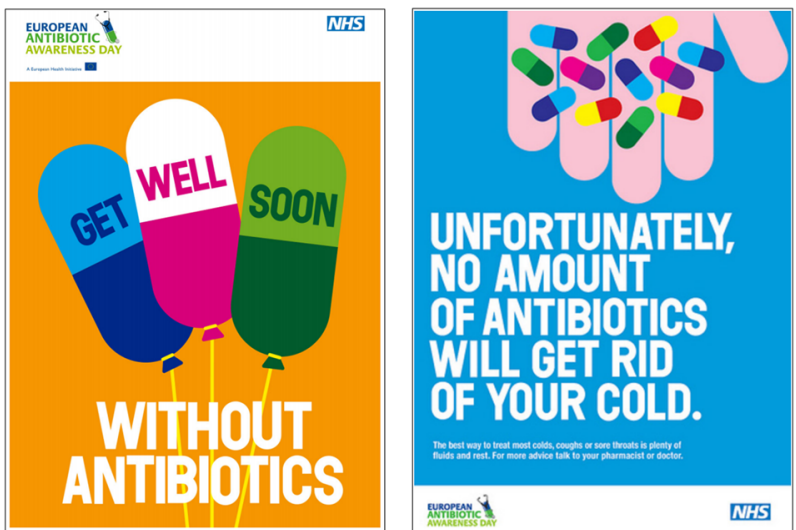

Fig. 15 Two posters produced for European Antibiotic Awareness Day, 2008. This figure is not covered by the Creative Commons Attribution 4.0 International License. Reproduced with permission of European Centre for Disease Prevention and Control (ECDC); copyright (C) ECDC [2015-2018]

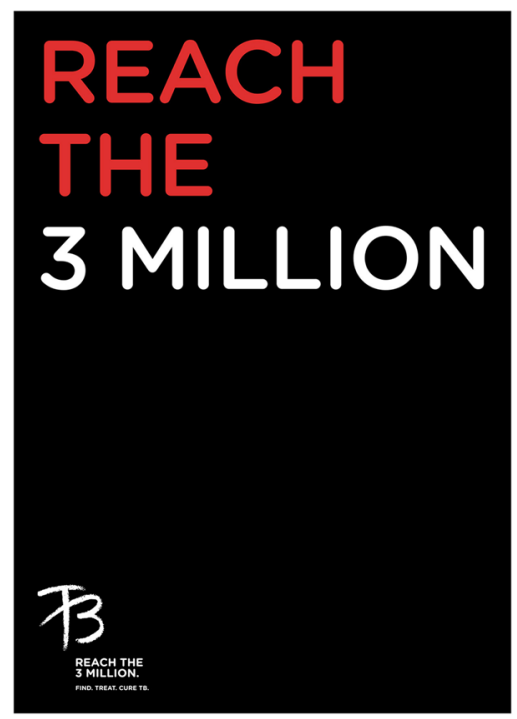

Fig. 16 Poster produced by the World Health Organisation as part of World TB day in 2014. This is the final poster in a series of three which together convey the message: 'Every year 9 million get sick with TB 3 million do not get the care they need. Help us to reach them.' This figure is not covered by the Creative Commons Attribution 4.0 International License. Reproduced with permission of $\mathrm{WHO}$; copyright (c) $\mathrm{WHO}$, all rights reserved

have done, to consider how space in pharmacies and the presentation of information can engage pharmacy users with AMR and its prevention (Walker et al., 2018). ${ }^{2}$ Even though co-design is a well-established process in the health sector (see Macdonald, 2017), for many of the non-designers in this project it was an entirely new way of working.

IDAPPS has engaged pharmacy users and workers, keen to contribute ideas and opinions about the presentation of information to raise awareness of AMR, and its location within the pharmacy. Their knowledge of their pharmacy community has helped shape the design proposals, and through this we hope to better educate and persuade people to take note and action. This aligns with a growing recognition that changing behaviours is multi-faceted, requiring integration of expertise across disciplines. Ashiru-Oredope and Hopkins (2015, p. 2929), for example, are explicit about the role of behavioural science:

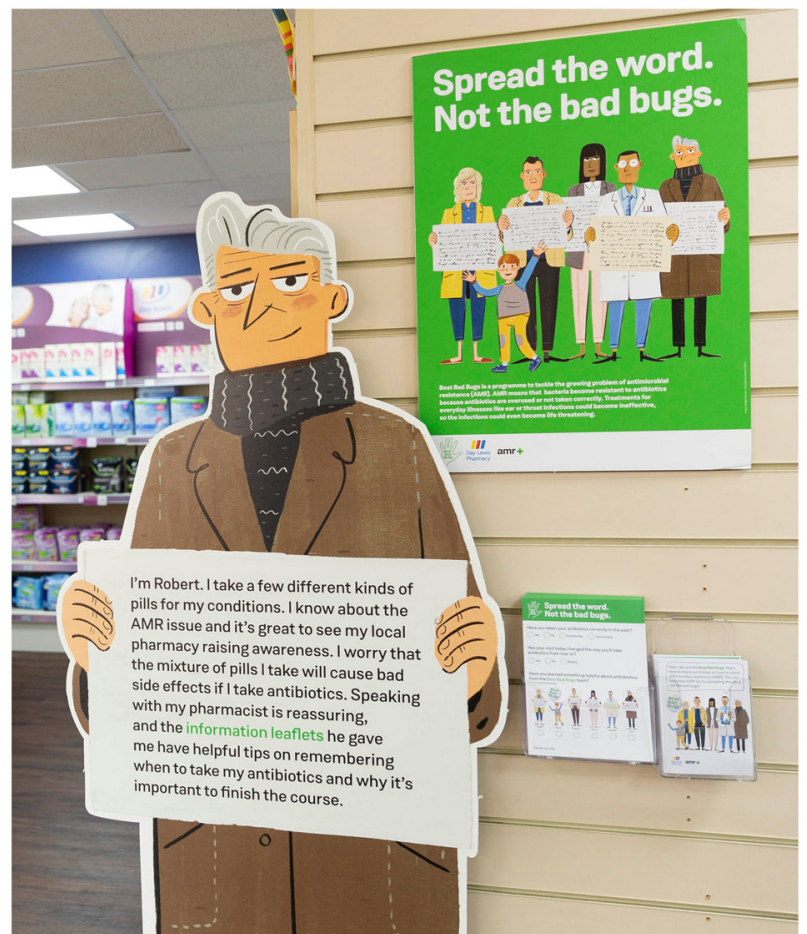

Fig. 17 One of the characters from the Beat Bad Bugs campaign produced by Design Science as part of the Information Design and Architecture in Persuasive Pharmacy Space: combating AMR' (IDAPPS) project. Though bearing no visual relationship to Isotype, the designers were inspired by the way the Neurath's found ways to engage people through stories they could relate to. This figure is not covered by the Creative Commons Attribution 4.0 International License. Reproduced with permission of the IDAPPS project; copyright (c) IDAPPS, all rights reserved

Future antimicrobial resistance campaigns need to be developed incorporating behavioural science to consider the messages and modalities that would be the most costeffective in reducing antibiotic prescribing whilst maximising the impact on people's knowledge, attitudes and behaviour.

The contribution information design can make in this context was acknowledged in a report by The Health Foundation (December 2015), 'Behavioural insights in health care: nudging to reduce inefficiency and waste':

'Information design both in terms of text and language (e.g. use of 'plain English' and behaviourally specific, concrete statements and presentation of risk) and appearance (e.g. colour, visual stimuli, images) may all influence how engaging or persuasive information is.'

The Neurath's would have agreed with this, not least because their approach to graphic communication was to make complex information readily understood by ordinary people. An important Isotype legacy (and one that underpins information design research and practice more generally) is a concern with both language and with visual presentation so that messages are presented clearly and with the needs of intended users in mind. The Neurath's concern to find ways to engage individuals and their respective local networks and communities, and to encourage people to take responsibility for their actions was integral to their method of working. Their method included collaboration and discussion between all those involved: scientists, clinicians, designers, writers, technicians and intended 
audiences. The relevance of this today in relation to AMR communication has been tested in the IDAPPS project, involving cross-disciplinary collaboration and user engagement, as well as consideration of the visual attributes of Isotype. Much health communication in the twenty-first century is focused on risk and prevention on a national and international scale (Mold and Berridge, 2013). This has seen the arrival of mass-media communication campaigns, including many that align with anti-microbial resistance, and in particular the use and misuse of antibiotics. It remains the case, however, that for many people it will be at an individual and local level where active engagement with AMR takes place. Work on the IDAPPS project suggests that community pharmacies provide an ideal space for AMR communication, aligning with the Neurath's TB work in the USA where their explanatory charts infiltrated community centres and church halls.

\section{Concluding remarks}

The fundamental Isotype legacy is that of the role of the transformer-the person who, in collaboration with specialists in a particular field, makes complex information clear so it can be easily understood. This is reflected in current information design research and practice. For many, however, the legacy of Isotype is its particular graphic style-the pictograms and stripped-down use of colour and shape-while the principles and rules that underpinned them are usually not understood or applied. But, following on from Isotype there are some particular verbal and graphic attributes that could usefully be explored in communicating information about AMR, including

- the use of scale and the simplification of images (as in the TB chart shown in Fig. 5) to attract attention and stimulate curiosity;

- the use of story-telling to engage people, as in the TB charts through emphasis on a man and his family and the effect that $\mathrm{TB}$ could have on them and their community;

- the distillation of verbal and pictorial information into manageable chunks, taking care not to overwhelm the reader with too much information;

- clear and straightforward language, using a direct and active voice.

Further, the person-in-the-street had not encountered anything like an Isotype chart before and would have been intrigued, and we have seen how Otto Neurath encouraged engagement through display in 'corner shops' frequently visited. The people-centred focus of the Neurath's work is relevant to AMR communication today. In the IDAPPS project, for example, one team member was inspired by the TB charts shown in Fig. 6 and remarked that:

There is something immediately capturing and engaging about other humans and faces. It's tangible and can be related to; we wanted to create a similar tangibility.

This influenced the example of AMR communication shown in Fig. 17, one of the outputs of the IDAPPS research project, and indicative of the creativity that designers can bring to communicating information about AMR. Through such creativity, design has the potential to disrupt expectations and to trigger curiosity and engagement, leading to understanding.

\section{Data availability}

Data sharing is not applicable to this article as no datasets were generated or analysed.

Received: 8 April 2018 Accepted: 21 January 2019

Published online: 26 February 2019

\section{Notes}

1 See: https://www.gov.uk/government/publications/european-antibiotic-awarenessday-and-antibiotic-guardian-posters-and-leaflets

2 See: www.amrpharmacy.org

\section{References}

Abraham C, Kools M (2012) Writing health communication: an evidence-based guide. Sage, London

Ashiru-Oredope D, Hopkins S (2015) Antimicrobial resistance: moving from professional engagement to public action. J Antimicrob Chemother 70:2927-2930

Black A, Luna P, Lund O, Walker S (2017) Information design: research and practice. Routledge, Abingdon

Burke C (2013a) Pictogram design: Vienna and beyond. In: Burke C, Kindel E, Walker S (eds) Isotype: design and contexts 1925-1971. Hyphen Press, London, pp. 499-521

Burke C (2013b) The Gesellschafts- und Wirtschaftsmuseum in Wein (Social and economic museum of Vienna), London: 1925-34. In: Burke C, Kindel E, Walker S (eds) Isotype: design and contexts 1925-1971. Hyphen Press, London, pp. 21-102

Burke C, Kindel E, Walker S (2013) Isotype design and contexts 1925-1971. Hyphen Press, London

Chaintarli K, Ingle SM, Bhattacharya A, Ashiru-Oredope D, Oliver I, Gobin M (2016) Impact of a United Kingdom-wide campaign to tackle antimicrobial resistance on self-reported knowledge and behaviour change. BMC Public Health 16:393

Coulter A, Entwistle V, Gilbert D (1998) Informing patients: an assessment of the quality of patient information materials. King's Fund, London

Eve M, Burke C (eds) (2010) From hieroglyphics to Isotype: a visual autobiography. Hyphen Press, London

Frascara J (2006) Designing effective communications: creating contexts for clarity and meaning. Allworth Press, New York, NY

Frascara J (2015) Information design as principled action: making information accessible, relevant, understandable and usable. Common Ground Publishing, Champaign, IL

Griffin D (2016) Posters for public health: WPA posters and national dialogues about health care in the United States. Commun Des 3(2):124-141

Ihara H (2013) Isotype in America: Otto Neurath and Rudolf Modley, 1930-9. In: Burke C, Kindel E, Walker S (eds) Isotype: design and contexts 1925-1971. Hyphen Press, London, pp. 298-353

Kinross, R (2013) The graphic information of Isotype 1925-1940. In Burke C, Kindel E, Walker S (eds) Isotype: design and contexts 1925-1971. Hyphen Press, London, pp. 107-177

Kinross R (2017) The lessons of Isotype for information design. In: Black A, Luna $\mathrm{P}$, Lund $\mathrm{O}$, Walker S (eds) Information design: research and practice. Routledge, Abingdon, pp. 107-116

Kleinschmidt HE (nd). A promising visual method of teaching, injured by imitation, goes begging for lack of appreciation. Undated typescript, Otto and Marie Neurath Isotype Collection, University of Reading [IC 8.2 KLE18/8]

Macdonald A (2017) Negotiating design within sceptical territory: lessons from healthcare. In: Tsekleves E, Cooper R (eds) Design for health. Routledge, Abingdon, pp. 311-327

MacDonald Ross M, Waller R (2000) The transformer revisited. Inf Des J 9 (2-3):177-93

McNulty C, Boyle P, Nichols T, Clappison P, Davey P (2007) Don't wear me outthe public's knowledge of and attitudes to antibiotic use. J Antimicrob Chemother 59(4):727-738

McNulty C, Nichols T, Boyle P, Woodhead M, Davey P (2010) The English antibiotic awareness campaigns: did they change the public's knowledge of and attitudes to antibiotic use? J Antimicrob Chemother 65(7):1526-1533

Mendelson M, Balasegram M, Jinks T, Pulcini C, Sharland M (2017) Antibiotic resistance has a language problem. Nature 545:23-25

Mold A, Berridge V (2013) The history of health promotion. In: Cragg L, Davies M, Macdowall W (eds.) Health promotion theory. Open University Press, Berkshire, pp. 3-19

NLM (US National Library of Medicine) (2011). Visual culture and public health: tuberculosis. https://www.nlm.nih.gov/exhibition/visualculture/tuberculosis. html. Accessed Mar 2018

Neurath M, Kinross R (2009) The transformer: principles of making Isotype charts. Hyphen Press, London

Neurath O (1944) The human approach to health education. Health Educ J 2 (2):61-6

Neurath O (1945) Health education through Isotype. Reprinted from The Lancet, 25 August. [8 pp document]

Neurath O, Kleinschmidt HE (1939) Health education by Isotype. American Public Health Association, New York, NY 
Raynor D, Dickenson D (2009) Key principles to guide development of consumer medicine information: content analysis of information design texts. Ann Pharmacother 43(4):700-6

Reading (1980) International Picture Language/Internationale Bildersprache. Department of Typography \& Graphic Communication, Reading, A facsimile reprint of the [1936] English edition

Rose G (1994) The use of ephemera with particular reference to blood and organ donation: a review of sources. Health Libr Rev 11:104-116

Schrauwen S, Roberts L, Wright R (2017) Can graphic design save your life? Graphic Design \&, London

Schriver K (1997) Dynamics in document design: creating texts for readers. John Wiley, New York, NY

Schreder G, Hynek N, Windhager F, Mayr E (2018) Rediscovering Isotype from a cognitive perspective. In Chapman P, Stapleton G, Moktefi A, Perez-Kriz S, Bellucci F (eds) Diagrammatic representation and inference. Diagrams 2018. Lecture notes in computer science. Springer, Cham, vol 10871

Stiff P (2005) Some documents for a history of information design. Inf Des J+Doc Des 13(3):216-228

Taylor S (1944) Battle for health. A primer for social medicine. Nicholson \& Watson, London, pp. 28-29

Tsekleves E, Cooper R (2017) Design for health: challenges, opportunities, emerging trends, research methods and recommendations. In: Cooper R, Tsekleves E (eds) Design for health. Routledge, Abingdon, pp. 388-408

Tufte E (1997) Visual explanations. Graphics Press, Cheshire

Tufte E (2001) The visual display of quantitative information. Graphics Press, Cheshire

Twyman M (ed) (1975) The significance of Isotype. In Graphic Communication Through ISOTYPE, published to accompany an exhibition of the same name held in the Library of the University of Reading. University of Reading, Reading, pp. 7-17

Walker S (2017) The contribution of typography and information design to health communication. In: Cooper R, Tsekleves E (eds) Design for health. Routledge, Abingdon, pp. 92-109

Walker S, Hignett S, Lim R, Parkhurst C, Samuel F, Mole M (2018) Design, architecture, pharmacy: making a difference to understanding anti-microbial resistance (AMR). In Christer K, Craig C, Wolstenholme D, (eds) Proceedings of the 5th European International Conference on Design4Health, Sheffield, UK, 4-6 September 2018. Sheffield Hallam University, Sheffield

Ward K, Hawthorne K (1994) Do patients read health promotion posters in the waiting room? A study in one general practice. Br J Gen Pract 44 (389):583-585
Wellcome (2015) Antibiotic resistance poorly communicated and widely misunderstood by UK public. https://wellcome.ac.uk/press-release/antibioticresistance-poorly-communicated-and-widely-misunderstood-uk-public Accessed Mar 2018

Woodhead M, Finch R (2007) Public education-a progress report. J Antimicrob Chemother 60(1, 1):i53-i55

\section{Acknowledgements}

This work has been generously supported by the Arts and Humanities Research Council Contract No. AH/R002053/1. My thanks to the 'Information design and architecture in persuasive pharmacy space: combating AMR' (IDAPPS) project team, and to the competition teams that attended the IDAPPS Ideas Lab for discussion around the Isotype approach to health communication.

\section{Additional information}

Competing interests: The author declares no competing interests.

Reprints and permission information is available online at http://www.nature.com/ reprints

Publisher's note: Springer Nature remains neutral with regard to jurisdictional claims in published maps and institutional affiliations.

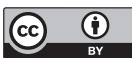

Open Access This article is licensed under a Creative Commons Attribution 4.0 International License, which permits use, sharing, adaptation, distribution and reproduction in any medium or format, as long as you give appropriate credit to the original author(s) and the source, provide a link to the Creative Commons license, and indicate if changes were made. The images or other third party material in this article are included in the article's Creative Commons license, unless indicated otherwise in a credit line to the material. If material is not included in the article's Creative Commons license and your intended use is not permitted by statutory regulation or exceeds the permitted use, you will need to obtain permission directly from the copyright holder. To view a copy of this license, visit http://creativecommons.org/ licenses/by/4.0/.

(C) The Author(s) 2019 